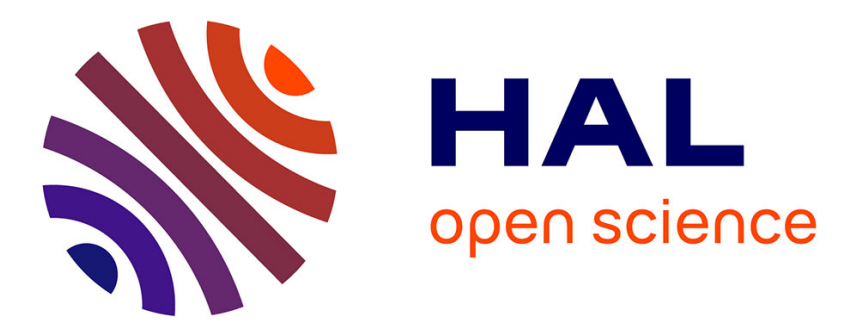

\title{
Prevalence, predicting factors and impact of internet use by patients with idiopathic pulmonary fibrosis: A cross-sectional observational study
}

M Le Garrec, C Rousseau, F Thépault, M Kerjouan, A Salé, Stéphane Jouneau

\section{To cite this version:}

M Le Garrec, C Rousseau, F Thépault, M Kerjouan, A Salé, et al.. Prevalence, predicting factors and impact of internet use by patients with idiopathic pulmonary fibrosis: A cross-sectional observational study. Respiratory Medicine and Research, 2021, 79, pp.100818. 10.1016/j.resmer.2021.100818 . hal03217253

\section{HAL Id: hal-03217253 \\ https://hal.science/hal-03217253}

Submitted on 5 May 2021

HAL is a multi-disciplinary open access archive for the deposit and dissemination of scientific research documents, whether they are published or not. The documents may come from teaching and research institutions in France or abroad, or from public or private research centers.
L'archive ouverte pluridisciplinaire HAL, est destinée au dépôt et à la diffusion de documents scientifiques de niveau recherche, publiés ou non, émanant des établissements d'enseignement et de recherche français ou étrangers, des laboratoires publics ou privés. 
Prevalence, predicting factors and impact of internet use by patients with idiopathic pulmonary fibrosis: A cross-sectional observational study.

Marianne Le Garrec ${ }^{1}$, Chloé Rousseau ${ }^{2}$, Fanny Thépault ${ }^{1}$, Mallorie Kerjouan ${ }^{1}$, Alexandre Salé$^{1}$, Stéphane Jouneau ${ }^{1,3}$.

1. Respiratory Diseases Department, Competence Centre for Rare Pulmonary Diseases, Pontchaillou University Hospital, Rennes, France

2. Centre d'Investigation clinique, Inserm 1414, CHU de Rennes, Université de Rennes 1, Rennes, France.

3. IRSET UMR 1085, Université de Rennes 1, Rennes, France.

Corresponding author:

Dr. Marianne Le Garrec

Department of Respiratory Medicine, Competence Centre for Rare Pulmonary Diseases, Pontchaillou Hospital, Rennes 1 University, 2 rue Henri Le Guilloux, 35033 Rennes Cedex 9, France.

Tel: $+33(0) 2.99 .28 .24 .78$

Fax: $+33(0) 2.99 .28 .24 .80$

Marianne.LEGARREC@ch-dinan.fr

Keywords: information, diagnosis, confidence, education, interstitial lung disease, Pirfenidone, Nintedanib

Word count : 990 
Idiopathic pulmonary fibrosis (IPF) is a fibrosing interstitial pneumonia of unknown aetiology. Communication between patients, families and physicians can be difficult at times; this is exacerbated by the fact that IPF is a rare condition that is poorly understood by patients and general population $(1,2)$, unlike other severe disease such as lung cancer; prognosis is seldom properly perceived by either patients or their families at diagnosis.

Little is known about how IPF patients or their offspring look for health information.

This study assess the proportion of IPF patients and their offspring that use the internet to obtain information and why they do so, identifies the factors predicting its use, and the impact of this use on how patients and their families view the results and their attitude towards their physician.

We conducted this monocentric observational cross-sectional study between May 2016 and June 2017 at Rennes University Hospital, Competence Centre for Rare Respiratory Diseases. The study was approved by the hospital Ethics Committee $\left(\mathrm{N}^{\circ} 16.72\right)$.

Consecutive patients with IPF, diagnosed during multidisciplinary discussion, were given two questionnaires adapted from Bouju et al. (3), one for them ("patient questionnaire"), another one for younger family members, children or cousins ("descendant questionnaire"), population of interest, younger and more likely to use the internet daily.

The questions focused on the patient's sociodemographic characteristics and their internet use, whether and why they attempted to obtain information about IPF, the websites consulted; they also were asked to estimate the usefulness of the research, how it influenced their understanding of the disease, and their attitude towards physicians. The final covered anxiety and depression (HADS questionnaire) and IPF-specific quality-of-life (ATAQ-IPF).

Only those questionnaires completed by 57 patients and 44 offspring of the 108 consecutive IPF patients given the document during the study period were suitable for inclusion. Most 
missing data were questionnaires not given back. Over half of the patients $(34 / 57 ; 60 \%)$ and $75 \%$ of descendants (33/44) reported using the internet for IPF research.

Concerning patients, mean age was $72.9 \pm 7.5$ years and the female/male ratio was $1 / 7.1$. Majority of patients $(31 / 52 ; 60 \%)$ used the internet daily and had already looked for health information on the internet $(34 / 56 ; 60.7 \%)$. Multivariate analysis revealed an association between internet use and a short interval between diagnosis and completing the questionnaire, and a smaller forced vital capacity (FVC). Almost half $(23 / 57 ; 40 \%)$ of our patients did not use the internet to find information about IPF, in contrast to their younger generation $(11 / 44,25 \%)$, because they were given sufficient information by their physician and were more confident in him.

Concerning descendants, most $(40 / 44 ; 90.9 \%)$ of the "offspring" used the internet daily. Almost all $(90.9 \%)$ had previously used the internet for health searches. The only significant predictor was a previous internet search for health purposes.

The figure lists the reasons why patients and their descendants used the internet; most of the time after diagnosis and before treatment began. The main search topics for patients were diagnosis $(28 / 34,82 \%)$, prognosis $(24 / 34,70 \%)$ and treatment $(22 / 34,65 \%)$; and prognosis, diagnosis and symptoms for descendants (respectively 82, 79 and 70\%). Most of the patients (26; 76\%) used community sites and institutional websites $(7 ; 20.5 \%)$.

Most IPF patients $(22 / 34 ; 65 \%)$ found internet information clear, understandable, easy to find and consistent with that given by their physician. All the patient and most of the descendants $(29 / 31 ; 93.6 \%)$ were more confident in their doctor when there was any inconsistency between the internet data and the information given by the pulmonologist.

Most patients $(22 / 34 ; 65 \%)$ and their descendants $(31 / 33 ; 94 \%)$ agreed that consulting the internet helped them to communicate with their doctor and to have more confidence in him (20/34 for both, $59 \%$ ). About $70 \%$ of the patients told their doctor about their internet searches. 
More than half our IPF patients (60\%) used the internet, as did even more $(75 \%)$ of their descendants. Those patients who used the internet logged on every day, had previously carried out health-related searches, and had a smaller predicted FVC. Most of these internet searches about IPF were done during the peri-diagnosis period. Internet use gave the patients a clearer understanding of the disease, and better communication with, and confidence in their physician.

Some studies that looked at the characteristics of older people using the internet found that age, gender and socioeconomic status was all significant influences (4).

The young descendants of our patients were frequent internet users who went online daily. The key factors predicting internet use by the patients in our study were their usual frequency of the internet use and previous internet searches about health topics. Baumann et al. has also shown that these two factors are more important predictors than socioeconomic status (5). We also found that patients with a recent diagnosis of IPF were significantly more likely to use the internet to find information about their disease.

The three main topics of interest, diagnosis, prognosis, and treatment have often been evaluated (6-8).

Patients and descendants were very positive about what they found on the internet, in agreement with the findings of previous studies (9), with a better understanding of the disease, which helped them be more active in their medical care.

Our study has some limitations, especially 51 patients (47.2\%) did not complete the questionnaire, and some questionnaires may have been filled by their spouses, which has already been described (10). There was probably also a memory bias for patients who had been diagnosed with IPF long before, and the fact that the questionnaire was given by the doctor himself could also have influenced the patients' answers. 
We conclude that most of our IPF patients and their descendants used the internet to obtain complementary information on the disease, although the information given by the physician was judged to be clear and sufficient. The internet was often used immediately after diagnosis.

The internet is part of everyday life, and physicians should exploit their internet resources, with websites for counselling IPF patients and their families. 


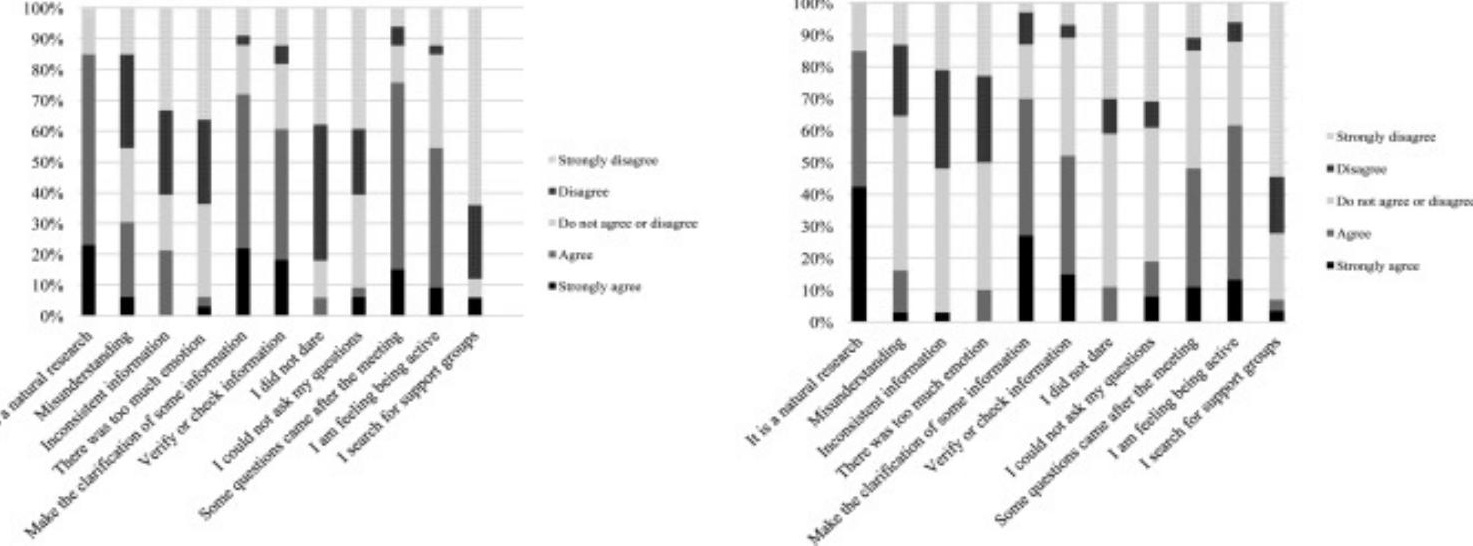

